\title{
Quantification of Fas protein in CSF of patients with neurocysticercosis
}

\author{
Quantificação da proteína Fas no LCR de pacientes com neurocisticercose \\ José Augusto Camargo, Paulo Henrique Ferreira Bertolucci
}

\begin{abstract}
Neurocysticercosis is a parasitic disease that affects the central nervous system. The objective of this study was to investigate the correlation between neuronal death evaluated by the quantification of Fas apoptotic factor and the different evolutive forms of neurocysticercosis accompanied or not by epileptic seizures. Methods: Cerebrospinal fluid samples from 36 patients with a diagnosis of neurocysticercosis divided into the following groups: active cystic form $(n=15), 9$ patients with and 6 without seizures, and calcified form $(=21), 9$ with and 12 without seizures. Fourteen patients comprised the control group. Fas protein concentrations were determined by ELISA. Results: Only the group of patients with calcified cysts without seizures presented cerebrospinal fluid levels of Fas similar to those of the control group. Higher levels were observed for the other groups. Conclusions: The present finding suggests high cerebrospinal fluid levels of soluble Fas protein, except for patients with calcified cysts without seizures. Significant differences were observed for the group with calcified cysts and seizures, suggesting greater neuronal damage in these patients. Replacement of the term inactive cyst with reactive inactive cyst is suggested.
\end{abstract}

Key words: neurocysticercosis, Fas ligand protein, cerebrospinal fluid, neuronal damage.

\section{RESUMO}

Neurocisticercose é uma doença parasitária que afeta o sistema nervoso central. O objetivo deste estudo foi investigar a correlação entre morte neuronal por meio da quantificação do fator apoptótico Fas e a presença de neurocisticercose nas suas diferentes fases evolutivas, acompanhadas ou não de crises epilépticas. Métodos: Foram analisadas amostras de líquido cefalorraquidiano em 36 pacientes com diagnóstico de neurocisticercose, determinando-se as concentrações da proteína Fas pelo método ELISA. Foram considerados os seguintes grupos: forma cística ativa $n=15$ ( 9 com crises, 6 sem crises), forma calcificada $n=21$ (9 com crises, 12 sem crises) e 14 pacientes (grupo controle). Resultados: Apenas o grupo com calcificações sem crises apresentou níveis de Fas semelhantes ao controle. Maiores níveis foram observados nos outros grupos. Conclusões: As formas ativa e calcificada apresentam níveis elevados da proteína Fas, exceto para as formas calcificadas sem crises. No grupo de calcificações com crise, observamos diferenças mais expressivas, sugerindo maior dano neuronal. Sugerimos a substituição da denominação "cisto inativo" por "cisto inativo reagente".

Palavras-Chave: neurocisticercose, proteína ligante Fas, líquido cefalorraquidiano, dano neuronal.

Neurocysticercosis (NC) is a term used to define involvement of the central nervous system (CNS) by the larval form of the tapeworm Taenia solium. This occurs when humans, who are the definitive host of the adult worm, also become an intermediate host that harbors the larval form in the CNS. NC shows an important incidence in developing countries, being the disease responsible for approximately 50,000 deaths every year, although growing migration to developed countries is increasing the number of diagnosed cases in those countries ${ }^{1}$.

Mature cysticerci remain viable in the brain parenchyma for a period of three to six years, a phase during which the cysticercus modulates the immune response of the host, preventing its own destruction and permitting the peaceful coexistence between the parasite and host ${ }^{2,3}$. In contrast, during the degenerative phase, the cysticercus is unable to suppress the action of the host immune system and is destroyed. The symptoms observed during this phase are generally associated with the inflammatory response that occurs in $\mathrm{NC}$, but also depend on the number, morphological type and localization of the cysts $^{4-6}$. Clinical manifestations of cysticercosis include seizures and dementia. Studies suggest that the patient remains asymptomatic as along as the cyst continues to be viable ${ }^{7,8}$.

The three evolutive phases of the cysticercus, i.e., viable, degenerative and calcified, can be identified by neuroimaging

Departamento de Neurologia e Neurocirurgia da Universidade Federal de São Paulo/Hospital São Paulo, São Paulo SP, Brazil.

Correspondence: José Augusto Camargo; Avenida Juscelino Kubitschek de Oliveira 753 / sala 11; 18035-060 Sorocaba SP - Brasil; E-mail: jacneuro@hotmail.com Support: FADA, CNPQ and FAPESP.

Conflict of interest: There is no conflict of interest to declare.

Received 04 July 2011; Received in final form 12 December 2011; Accepted 19 December 2011 
methods. In contrast, analysis of cerebrospinal fluid (CSF) provides important information about the inflammatory response that occurs in NC, permitting a better understanding of the interaction between the parasite and host. The classification of $\mathrm{NC}$ lesions into active or inactive based only on imaging criteria seems increasingly more inadequate since inactive forms detected by imaging exams might present important clinical and $\mathrm{CSF}^{2}$.

Recent studies have tried to identify markers able to detect brain damage in diseases such as $\mathrm{NC}^{9}$. However, the efficacy of these markers seems to be related to clinically and laboratory confirmed overtly active disease, with inflammatory activity being detected in most cases. A lower sensitivity of some markers to certain types of brain lesions has also been demonstrated ${ }^{10}$. A series of biochemical and morphological events lead to cell death, a sequence generically called programmed cell death (PCD). In contrast to necrotic cell death, PCD is an active process in which cells are dying and are removed safely without causing inflammation.

Among the markers of neuronal death, Fas protein has been widely studied. Fas belongs to the tumor necrosis factor (TNF) receptor superfamily and is the main proapoptotic protein ${ }^{11}$. Interaction of the soluble form of Fas protein with its receptor (FasL) leads to the formation of a cell death-inducing signaling complex that activates different types of caspases, causing mitochondrial damage and, finally, proteolytic death ${ }^{12}$.

The apoptotic process involves the participation of affected cells in the cascade of self-destruction that culminates in the degradation of DNA through the activation of endonucleases, cell disintegration and the formation of "apoptotic bodies" ${ }^{\prime \prime}$.

Since NC can result in cell death, it would be of clinical importance to determine the type of cell death that occurs during the different cystic phases of the disease and whether the presence of seizures interferes with the pattern of death observed. Therefore, the objective of the present study was to quantify soluble Fas protein in CSF of patients with active and calcified NC with or without epileptic seizures.

\section{METHODS}

\section{Patients}

All patients included in the study were selected prospectively among patients submitted to CSF puncture as requested by the physician. Patients with NC were diagnosed based on a combination of imaging findings [cranial computed tomography $(\mathrm{CT})$ and brain magnetic resonance (MR) imaging], CSF alterations, including an immunoenzymatic reaction to NC, epidemiological criteria and clinical findings according to the criteria of Del Brutto et al. ${ }^{4}$.

Using the classification suggested by Carpio et al. ${ }^{14}$, with modifications, the patients were divided into the following five groups, according to the evolutive phase of the cysticercus in the absence of signs of an inflammatory reaction upon imaging and CSF analysis:

1) Active or viable cysts without seizures $(n=6)$ : patients presenting one or more cysts in the absence of signs of an inflammatory reaction and no seizures.

2) Active or viable cysts with seizures ( $n=9)$ : patients presenting one or more cysts in the absence of signs of an inflammatory reaction and seizures.

3) Inactive or calcified cysts without seizures $(n=12)$ : patients presenting one or more calcified cysts in the absence of signs of an inflammatory reaction and no seizures.

4) Inactive or calcified cysts with seizures ( $n=9)$ : patients presenting one or more calcified cysts in the absence of signs of an inflammatory reaction and seizures.

5) Control group $(\mathrm{n}=14)$ : patients presenting no neurological or systemic alterations who were submitted to lumbar puncture for spinal anesthesia due to other reasons, such as minor orthopedic surgery or surgery for inguinal hernia correction.

All patients with seizures who presented signs of hydrocephalus and fever, and whose last seizure episode occurred within a period of less than 4 days and more than 60 days were excluded from the study.

Patients included in the study who belonged to the group with inactive or calcified cysts were submitted to CSF puncture for the investigation of possible reinfestation with cysticerci associated with symptoms, such as limb paresthesia, dizziness, vertigo and tinnitus. These symptoms were diagnosed after clinical investigation to be part of osteoarticular diseases of the spine and vestibular system disorders. CSF puncture was performed within a period of 4 to 30 days after the last seizure episode in patients of the groups with epileptic seizures.

All subjects were subjected to CT scan or brain MR. All subjects were submitted to lumbar puncture and CSF cytomorphological examination.

The project was approved by the Ethics Committee of Universidade Federal de São Paulo (UNIFESP, process 0857/05).

\section{Collection of cerebrospinal fluid samples}

CSF samples were collected by the responsible physician after the patient had signed a free informed consent form according to the guidelines of the Scientific Department of the Brazilian Academy of Neurology and UNIFESP. With the patient in the sitting position, lumbar puncture was performed in the L4/L5 intervertebral 
space using disposable Quincke needles (23 G x $90 \mathrm{~mm}$ or $22 \mathrm{G}$ x $90 \mathrm{~mm}$ ) with a short bevel. Samples containing red blood cells due to traumatic lumbar puncture were discarded. For the control group, CSF samples were collected at the time of lumbar puncture for the surgical procedure before injection of the anesthetic. Samples from patients with a diagnosis of $\mathrm{NC}$ were transported on ice, divided into aliquots and frozen at $-70^{\circ} \mathrm{C}$ until the time for processing at the laboratory of the Discipline of Experimental Neurology, UNIFESP.

\section{Determination of Fas protein concentration by ELISA}

The concentration of soluble Fas in CSF of the patients was measured by ELISA using the Quantikine kit (R\&D Systems) according to manufacturer instructions. Briefly, $100 \mu \mathrm{L}$ of the CSF sample or different concentrations of recombinant human soluble Fas provided for construction of the standard curve $(62.5,125,250,500,1000,2000 \mathrm{pg} / \mathrm{mL})$ were diluted in reaction buffer and incubated in duplicate for two hours at room temperature. The wells were washed three times with phosphate-buffered saline, and the biotinylated secondary antibody against human soluble Fas (50 ng/mL) was added. The plates were incubated for two hours at room temperature. After repeated washes (four times), the samples were incubated with HRP-conjugated streptavidin for 30 minutes. Bound antigen was detected by incubation with tetramethylbenzidine for 30 minutes. The reaction was stopped by the addition of $2 \mathrm{~N}$ sulfuric acid as blocking buffer. Optical densities were read at 450 $\mathrm{nm}$ over the first 30 minutes, with correction at 540 and $570 \mathrm{~nm}$.

\section{Statistical analysis}

Fas concentrations were analyzed by the $t$-test for independent samples. ANOVA or the F test was used to compare all groups as a whole. If a significant difference was detected $(p<0.05)$, multiple comparisons were performed to determine between which groups the difference occurred.

\section{RESULTS}

Fifty patients (27 men and 23 women) ranging in age from 19 to 59 years were studied. The mean age was 38.8 years (standard deviation 8.5).

The samples were classified into active cysts, calcified cysts and controls, and the groups were then subdivided into patients with and without seizures. All patients were submitted to cranial CT or MR in order to be included in the study. The CT or MR images and CSF analysis, consisting of cytomorphological examination, protein quantification, electrophoresis, glucose and chloride measurement, revealed no signs of an inflammatory reaction in any of the patients. All patients of the group with active cysts presented multiple intraparenchymatous cysts, eight patients of the group with calcified cysts presented single intraparenchymatous calcification (three of the group with seizures and five of the group without seizures) and the remaining patients presented multiple calcified cysts. Images showing the presence of 6 to 100 cysts were defined as multiple cysts and classified as moderate infestation according to García et al. ${ }^{15}$. Among the four groups with NC studied, only the group of patients with calcified cysts without seizures presented CSF levels of Fas similar to those of the control group. Higher levels were observed in the other groups, but statistical analysis only revealed a significant difference when patients with calcified cysts and seizures were compared to the control group and to the group with calcified cysts without seizures, and when the latter was compared to the group with viable cysts without seizures. The percent increase in CSF levels of Fas was 36\% $(p=0.01), 55 \%(p=0.038)$ and $85 \%(p=0.011)$ in the groups of patients with active cysts without seizures, active cysts with seizures and calcified cysts with seizures, respectively, when compared individually to the control group.

In the group with calcified cysts, all patients were from rural areas, and no significant differences in CSF Fas levels were observed between patients with single and multiple intraparenchymatous calcification. The average normal reference value of Fas obtained for the control group by the immunoenzymatic method was $208.00 \mathrm{pg} / \mathrm{mL}$. In contrast, an increase of Fas concentrations compared to the control group was observed in patients with viable and calcified cysts, except for the group of calcifications without seizures, as well as in patients of the same group with seizures compared to those without seizures (Table). This finding suggests the occurrence of apoptotic activity accompanied by neuronal death in the two groups. However, a significant difference was only observed when the group of calcified cysts with seizures was compared to the control group and to the group of calcified cysts without seizures.

Table. Quantification of soluble Fas protein in the CSF of the different groups studied.

\begin{tabular}{lccc} 
Fas concentration $(\mathrm{pg} / \mathrm{mL})$ & Mean & $\begin{array}{r}\text { Standard } \\
\text { deviation }\end{array}$ & $\begin{array}{c}\text { Standard } \\
\text { error }\end{array}$ \\
\hline Control & 208.00 & 51.24 & 13.70 \\
Active cysts with seizures & 322.75 & 137.05 & 45.68 \\
Active cysts without seizures & 283.11 & 57.53 & 23.49 \\
Calcification with seizures & 385.09 & 162.39 & 54.13 \\
Calcification without seizures & 193.17 & 56.24 & 16.23 \\
\hline
\end{tabular}




\section{DISCUSSION}

Apoptosis participates in various vital physiological processes, such as embryo development, involution of the mammary gland after breast-feeding, control of tumor cell proliferation and regulation of immune cell populations. Mutations in genes that trigger the apoptotic process are the cause of different diseases ${ }^{16,17}$. Since cell death is essential for life, it should follow a meticulous program. Any disturbance in this process, i.e., excessive or deficient death of cells, can cause a variety of diseases ${ }^{18}$. Excessive apoptosis may lead to neurodegenerative diseases (Alzheimer's and Parkinson's disease), secondary lesions after ischemia and osteoporosis, and can actively participate in parasitic diseases such as $\mathrm{NC}^{19}$. In the present study, the Fas levels observed in the two cystic forms of NC (active and calcified), except for calcified cysts without seizures, might be related to the activation of proapoptic cascades in neighboring neuronal cells as a reaction to these structures. The main clinical manifestations of NCC are epileptic seizures. These manifestations are directly associated with altered synaptic transmission, which results from changes in the concentrations of amino acid neurotransmitters in the CNS.

Numerous studies have measured Fas protein levels in blood of patients with different neoplastic, infectious, autoimmune and degenerative diseases, whereas studies discussing Fas measurement in CSF are scarce ${ }^{20}$. Elevated Fas levels are observed in patients in the advanced phase of diseases compared to those in the early stage. Mogi et al. ${ }^{21}$ found elevated tissue and CSF concentrations of soluble Fas in nigrostriatal dopaminergic neurons of patients with Parkinson's disease compared to the control group. Ciusani et al. ${ }^{22}$ investigated soluble Fas levels in CSF of patients with multiple sclerosis compared to patients with other types of neurological diseases and healthy controls. The authors concluded that the participation of soluble Fas in the pathogenesis of multiple sclerosis suggests that a lower rate of apoptosis in CSF might be a characteristic of the disease, thus demonstrating the importance of Fas protein for the detection of neurological diseases, especially those related to dementia. In this respect, Zhou et al. ${ }^{23}$ quantified soluble Fas levels in blood and CSF of patients with multiple sclerosis. Analysis of the two types of samples showed significantly elevated soluble Fas levels in patients in the active phase of disease compared to those in the inactive phase and to the control group. Martínez et al..$^{24}$ evaluated CSF concentrations of soluble Fas and interleukin 6 (IL-6) in ten patients with dementia of the Alzheimer type and ten control subjects, and detected a significant increase in soluble Fas and IL-6 concentrations in dementia patients compared to the control group and non-dementia patients. Felderhoff-Mueser et al. ${ }^{25}$ observed high concentrations of soluble Fas in children with hydrocephalus, whereas the control group presented levels below the detection limit. Towfighi et al. ${ }^{26}$ concluded that soluble
Fas concentration is elevated in CSF of patients with HIV who present symptoms of dementia and it is correlated with the severity of the condition.

In the study of Owen-Schaub et al. ${ }^{27}$, elevated blood levels of soluble Fas in patients with melanoma were correlated with a poor prognosis and lower survival. This marker was found to be useful for the evaluation of disease progression and for the establishment of therapeutic strategies. In most studies, blood levels of Fas are compared between patients with diseases and control groups or patients without disease with normal reference values, being defined in different protocols such as that of the R\&D Systems kit used in this study. However, normal reference values of Fas in CSF need to be established for patients without disease. CSF levels of Fas are generally compared between the early and advanced stages of the same disease.

In view of the results obtained, discussion of the term "inactive cyst" proposed by Sotelo et al. ${ }^{28}$ and Carpio et al. ${ }^{14}$, with modifications, is necessary. We often observe that patients with calcified NC, or even physicians and healthcare professionals who are not familiar with the disease, falsely assume that the disease is resolved, harmless or cured, and will not result in further damage when analyzing the reports or results of imaging exams (CT and MR) containing the expression "inactive cyst". Although referring to the state of the parasite, modification of this classification is of the utmost importance since brain tissue containing calcified cysts ${ }^{29}$. We therefore propose replacement of the term "inactive cyst" with "reactive inactive cyst" to indicate the presence of a substance resulting from the death of a cysticercus that provokes a reaction.

The present results led us to conclude that an increase in CSF levels of Fas in patients with calcified and viable cysts presenting seizures and in patients with viable cysts without seizures indicates the presence of apoptosis in the brain parenchyma. For patients with calcified cysts, no significant differences in CSF Fas levels were observed between those presenting single and multiple intraparenchymatous calcification. One conclusion that can be drawn is that the presence of elevated CSF levels of Fas reflects the occurrence of neuronal injury and death due to active apoptosis.

Further studies are necessary to better understand the signaling pathways involved in apoptosis whose participants are proteins encoded by specific genes involved in the process of apoptosis. In this respect, the morphological and biochemical aspects of cell death due to apoptosis in different diseases, including NC, need to be better investigated.

Despite the absence of inflammatory signs in the imaging exams and CSF of patients with $\mathrm{NC}$, a dynamic metabolic and inflammatory reaction might occur in the brain parenchyma. The present results emphasize the importance of considering $\mathrm{NC}$ as a progressive and active disease, even when the cysts are in the calcified phase. Replacement of the term "inactive cyst" with "reactive inactive cyst" is suggested. 
1. Engels D, Urbani C, Belotto A, Meslin F, Savioli L. The control of human (neuro)cysticercosis: which way forward? Acta Trop 2003;87:177-182.

2. Takayanagui OM, Leite JP. Neurocisticercose. Rev Soc Bras Med Trop 2001;34:283-290.

3. Grewal JS, Kaur S, Bhatti G, et al. Cellular immune responses in human neurocysticercosis. Parasitol Res 2000;86:500-503.

4. Del Brutto OH, Rajshekhar V, White Jr AC, et al. Proposed diagnostic criteria for neurocysticercosis. Neurology 2001;57:177-183.

5. Patel R, Jha S, Yadav RK. Pleomorphism of the clinical manifestations of neurocysticercosis. Trans R Soc Trop Med Hyg 2006;100:134-141.

6. Takayanagui OM, Odashima NS. Clinical aspects of neurocysticercosis. Parasitol Int 2006;55:S111-S115.

7. Ostrosky-Zeichner L, Estañol B. Immunopathogenesis of neurocysticercosis: is damage mediated by the host immune response? Int J Parasitol 1999:29:649-650.

8. WhiteACJr.Neurocysticercosis:updates on epidemiology, pathogenesis, diagnosis, and management. Ann Rev Med 2000;51:187-206.

9. Lima JE, Takayanagui OM, Garcia LV, Leite JP. Neuron-specific enolase in patients with neurocysticercosis. J Neurol Sci 2004;217:31-35.

10. Kessler FHP, Woody G, Portela LVC, et al. Brain injury markers (S100B and NSE) in chronic cocaine dependents. Rev Bras Psiquiatr 2007;29:134-139.

11. Krantic S, Mechawar N, Reix S, Quirion R. Apoptosis-inducing factor: a matter of neuron life and death. Prog Neurobiol 2007;81:179-196.

12. Nagata S, Golstein P. The Fas death factor. Science 1995;267:14491456.

13. Wyllie $\mathrm{AH}$. The biology of cell death in tumors. Anticancer Res 1985;5:131-136.

14. Carpio A, Placencia M, Santillán F, Escobar A. A proposal for classification of neurocysticercosis. Can J Neurol Sci 1994;21:43-47.

15. García HH, Evans CA, Nash TE, et al. Current consensus guidelines for treatment of neurocysticercosis. Clin Microbiol Rev 2002;15:747-756.

16. Debatin KM. Activation of apoptosis pathways by anticancer treatment. Toxicol Lett 2000;113:41-48.
17. Hengartner MO. The biochemistry of apoptosis. Nature 2000;407:770-776.

18. Anazetti MC, Melo PS, Durán N, Haun M. Comparative cytotoxicity of dimethylamide-crotonin in the promyelocytic leukemia cell line (HL60) and human peripheral blood mononuclear cells. Toxicology 2003;188:261-274.

19. Marín-García J, Goldenthal MJ. Mitochondria play a critical role in cardioprotection. J Card Fail 2004;10:55-66.

20. Badley AD, Roumier T, Lum JJ, Kroemer G. Mitochondrion-mediated apoptosis in HIV-1 infection. Trends Pharmacol Sci 2003;24:298-305.

21. Mogi M, Harada M, Kondo T, et al. The soluble form of Fas molecule is elevated in parkinsonian brain tissues. Neurosci Lett 1996;220:195-198.

22. Ciusani E, Frigerio S, Gelati, et al. Soluble Fas (Apo-1) levels in cerebrospinal fluid of multiple sclerosis patients. J Neuroimmunol 1998;82:5-12.

23. Zhou WB, Hans L. Detection of the soluble form of the Fas molecule in patients with multiple sclerosis. Hunan Yi Ke Da Xue Xue Bao 2000;25:39-41.

24. Martínez M, Fernández-Vivancos E, FrankA, De la Fuente M, Hernanz A. Increased cerebrospinal fluid Fas (Apo-1) levels in Alzheimer's disease. Relationship with IL-6 concentrations. Brains Res. 2000;869:216-219.

25. Felderhoff-Mueser U, Herold R, Houchlaus F, et al. Increases cerebrospinal fluid concentrations of soluble Fas (CD95/Apo-1) in hydrocephalus. Arch Dis Child 2001;84:369-372.

26. Towfighi A, Skolasky RL, Hillaire CSt, Conant K, McArthur JC. CSF soluble Fas correlates with the severity of HIV-associated dementia. Neurology 2004;62:654-656.

27. Owen-Schaub L. Soluble Fas and cancer. Clin Cancer Res 2001;7:11081109.

28. Sotelo J, Guerrero V, Rubio-Dannadieu F. Neurocysticercosis: a new classification based on active and inactive forms. A study of 753 cases. Arch Intern Med 1985;145:442-445.

29. Camargo JA. Estudo dos aminoácidos neurotransmissores e da proteína Fas no líquor nas diferentes fases da neurocisticercose humana [dissertação]. São Paulo: Universidade Federal de São Paulo; 2010. 